\title{
Christopher Walsh: Pioneer and innovator in antibiotic and natural product chemical biology
}

\author{
The Journal of Antibiotics (2014) 67, 5-6; doi:10.1038/ja.2013.118
}

$\mathrm{F}$ or over four decades, Christopher Walsh has bridged the disciplines of Chemistry and Biology to greatly advance our understanding of primary and secondary metabolism. The application of this body of work in medicine has been profound, especially influencing (but not limited to) the fields of antibiotic discovery, cancer chemotherapy and immune suppression. Walsh began his independent career at the Massachusetts Institute of Technology (MIT) formally in the Department of Chemistry, but also associated with the Department of Biology. ${ }^{1}$ This was an unusual arrangement at the time, but presaged the development of the multidisciplinary field that we now call Chemical Biology. Indeed Walsh has been at the forefront of this area inspiring legions along the way. At MIT he authored the first of his three books, Enzymatic Reaction Mechanisms. ${ }^{2}$ A hefty tome that was the 'gateway drug' (to abuse a term) for many students, including myself, to the application of chemical thought and instinct to biological reactions. Its clear writing style and logical flow was to be a hallmark of Walsh's over 800 publications. The work at MIT included pioneering research on cofactor enzymology, including enzymes requiring flavin and pyridoxal phosphate among others. Out of these interests came efforts to development and characterize 'suicide substrates' that exploit enzyme mechanisms to uncover reactive enzymeinactivating species, many of which find use in drug discovery. Walsh also took on the challenge of department Chair at that time, initiating what was to become a long-standing parallel career in university administration.

In 1987, Walsh moved to Harvard Medical School (HMS) to head a new amalgamated department, Biological Chemistry and Molecular Pharmacology. Here Walsh's research moved further towards the exploration of the chemical biology of medically relevant topics. Efforts to explore the enzymology of the protein kinases and their cognate phosphatases important to cancer and the activity of immunophillins, proteins involved in the immune suppressing activity of compounds such as cyclophilin, were initiated during the first half-decade of Walsh's tenure at HMS. He also took on yet another leadership position as President of the Dana Farber Cancer Institute.

In the early 1990s, Walsh along with Patrice Courvalin of the Pasteur Institute in Paris, deciphered the molecular mechanism of resistance to the antibiotic vancomycin, which had just emerged as a significant clinical problem. ${ }^{3}$ This project has its roots in Walsh's earlier exploration of the mechanism of inhibition of alanine racemase by $\beta$-fluroalanine in late 1970 s, the enzyme that generates
D-alanine essential for bacterial cell wall synthesis and vancomycin activity. At the same time, his interests in the biosynthesis of the siderophore enterobactin were gaining momentum. ${ }^{4}$ The realization that the biosynthesis of this non-ribosomal peptide required a phosphopantetheinyl unit to be covalently labeled to the synthetase providing a flexible arm for peptide assembly ushered in a new emphasis on natural product biosynthesis in Walsh's lab. The characterization and cloning of the first active phosphopantetheinyl transferases that activate both non-ribosomal and polyketide synthetases ${ }^{5}$ transformed the field of natural products in a profound way. This work, coming at a time when Walsh had just stepped away from university and hospital administration, was to usher in an era of intense creativity and productivity in his career. This has included efforts to explore the biosynthesis of antibiotics (glycopeptides, microcins, aminocoumarins, macrolides, tyrocidine, bacilysin, to name only a few) and other natural products (aspercillins, rapamycin, staurosporine, holomycin, kutznerides, etc. as well as numerous siderophores). At the same time, Walsh continued to bring together ideas from disparate fields in a cogent series of influential review articles that serve as signposts along the trajectory of natural product biosynthesis research over the past two decades (for example, see references 6-10). During this period he also authored two highly influential books, one on antibiotics $^{11}$ and the other on posttranslational modification of proteins. $^{12}$

Walsh's efforts to explore the chemistry of life have dominated research at the interface of medicine and fundamental chemistry and biology for the past four decades. In June 2013, he decided to close his lab leaving a legacy not only of his incredibly influential published work but also a remarkable family of over 260 graduate students and postdoctoral fellows who have worked with him. This issue of the Journal of Antibiotics brings together not only a review from Walsh himself, expertly pointing us in the direction of new antibiotics, but also contributions from his colleagues, trainees and friends who have gathered to report some of their research in tribute to this remarkable mentor and colleague.

Gerard D Wright

Department of Biochemistry and Biomedical Sciences, M. G. DeGroote Institute for Infectious Disease Research, DeGroote School of Medicine, McMaster University, Hamilton, Ontario, Canada E-mail: wrightge@mcmaster.ca 
1 Walsh, C. T. Catalysis at the intersection of biology, chemistry, and medicine. J. Biol. Chem. 285, 29681-29689 (2010)

2 Walsh, C. T. Enzymatic Reaction Mechanisms, 978 (W.H. Freeman \& Co., 1978)

3 Bugg, T. D., Wright, G. D., Dutka-Malen, S., Arthur, M., Courvalin, P. \& Walsh, C. T. Molecular basis for vancomycin resistance in Enterococcus faecium BM4147: biosynthesis of a depsipeptide peptidoglycan precursor by vancomycin resistance proteins VanH and VanA. Biochemistry 30, 10408-10415 (1991).

4 Rusnak, F., Sakaitani, M., Drueckhammer, D., Reichert, J. \& Walsh, C. T. Biosynthesis of the Escherichia coli siderophore enterobactin: sequence of the entFgene, expression and purification of EntF, and analysis of covalent phosphopantetheine. Biochemistry 30, 2916-2927 (1991).

5 Lambalot, R. H. et al. A new enzyme superfamily-the phosphopantetheinyl transferases. Chem. Biol. 3, 923-936 (1996).
6 Walsh, C. T. The chemical versatility of natural-product assembly lines. Acc. Chem Res. 41, 4-10 (2008)

7 Walsh, C. T. Polyketide and nonribosomal peptide antibiotics: modularity and versatility. Science 303, 1805-1810 (2004).

8 Walsh, C. T., Fisher, S. L., Park, I. S., Prahalad, M. \& Wu, Z. Bacterial resistance to vancomycin: five genes and one missing hydrogen bond tell the story. Chem. Biol. 3, 21-28 (1996).

9 Walsh, C. T. \& Fischbach, M. A. Natural products version 2.0: connecting genes to molecules. J. Am. Chem. Soc. 132, 2469-2493 (2010).

10 Walsh, C. Enabling the chemistry of life. Nature 409, 226-231 (2001).

11 Walsh, C. T. Antibiotics: Actions, Origins, Resistance, pp 355 (ASM Press, 2003).

12 Walsh, C. T. Posttranslational Modification of Proteins: Expanding Nature's Inventory, 576 (Roberts and Company Publishers, 2005). 